\title{
The use of contract licensed nursing staff in U.S. nursing homes.
}

\author{
Meg Bourbonniere \\ Yale Univerity \\ Zhanlian Feng \\ Brown University \\ Orna Intrator \\ Brown University \\ Joseph Angelelli \\ Pioneer Network \\ Vincent Mor \\ Brown University \\ Follow this and additional works at: https://jdc.jefferson.edu/nursfp \\ See next page for additional authors \\ Part of the Nursing Commons \\ Let us know how access to this document benefits you
}

\section{Recommended Citation}

Bourbonniere, Meg; Feng, Zhanlian; Intrator, Orna; Angelelli, Joseph; Mor, Vincent; and Zinn, Jacqueline S., "The use of contract licensed nursing staff in U.S. nursing homes." (2006). College of Nursing Faculty Papers \& Presentations. Paper 26.

https://jdc.jefferson.edu/nursfp/26

This Article is brought to you for free and open access by the Jefferson Digital Commons. The Jefferson Digital Commons is a service of Thomas Jefferson University's Center for Teaching and Learning (CTL). The Commons is a showcase for Jefferson books and journals, peer-reviewed scholarly publications, unique historical collections from the University archives, and teaching tools. The Jefferson Digital Commons allows researchers and interested readers anywhere in the world to learn about and keep up to date with Jefferson scholarship. This article has been accepted for inclusion in College of Nursing Faculty Papers \& Presentations by an authorized administrator of the Jefferson Digital Commons. For more information, please contact: JeffersonDigitalCommons@jefferson.edu. 
Authors

Meg Bourbonniere, Zhanlian Feng, Orna Intrator, Joseph Angelelli, Vincent Mor, and Jacqueline S. Zinn 


\title{
As submitted to:
}

\section{Medical Care Research and Review}

\author{
And later published as:
}

\section{"The Use of Contract Licensed Nursing Staff in U.S. Nursing Homes" \\ Vol. 63, No. 1, 88-109 (Feb. 2006) \\ DOI: $10.1177 / 1077558705283128$}

\author{
Meg Bourbonniere, $\mathrm{PhD}, \mathrm{RN}($ Corresponding) Zhanlian Feng, $\mathrm{PhD}$ \\ Yale University School of Nursing Brown University \\ 100 Church Street South, P.O. Box $9740 \quad$ Box G-ST220 \\ New Haven, CT 06536-0740 Providence, RI 02912 \\ Phone: (203) 737-5162 Phone: (401) 863-9356 \\ Fax: (203) 785-6455 Fax: (401) 863-3489 \\ Email: meg.bourbonniere@yale.edu $\quad$ Email: Zhanlian_Feng@Brown.edu \\ Orna Intrator, $\mathrm{PhD} \quad$ Joseph Angelelli, $\mathrm{PhD}$ \\ Brown University Director of Networking \& Development \\ Box G-ST208 Pioneer Network \\ Providence, RI $02912 \quad$ P.O. Box 18648 \\ Phone: (401) 863-3579 Rochester, New York 14618 \\ Fax: (401) 863-3489 Phone: 814-574-4331 \\ Email: Orna_Intrator@Brown.edu_joe.angelelli@pioneernetwork.net
}


Vincent Mor, $\mathrm{PhD}$

Brown University, Community Medicine

Box G-H1

Providence, RI 02912

Phone: (401) 863-3490

Fax: (401) 863-3489

Email: Vincent_Mor@Brown.edu
Jacqueline S. Zinn, PhD

Temple University

413 Ritter Annex

Philadelphia, PA 19122

Phone: (215) 204-1684

Fax: (215) 204-3851

Email: jacqueline.zinn@temple.edu

Key Words: nursing home staffing, personnel staffing and scheduling, temporary staff, quality of health care

\section{Acknowledgments}

Support for this project was provided by the Agency for Healthcare Research and Quality (HS 00011-16), the John A. Hartford Foundation (Building Academic Geriatric Nursing Capacity) and the National Institute on Aging (\#AG-11624). Dr. Bourbonniere was a postdoctoral research fellow in the Center for Gerontology and Health Care Research at Brown University when this study was conducted. 


\begin{abstract}
The extent to which nursing homes rely on the use of contracted licensed staff, factors associated with this staffing practice, and the resultant effect on the quality of resident care has received little public attention. We merged the On-line Survey Certification and Reporting System database with the Area Resource File from 1992 through 2002, and regressed organizational and market level variables on the use of $\geq 5 \%$ contract full-time equivalent (FTE) registered nurses $(\mathrm{RN})$ and licensed practical nurses (LPN). Since 1997, the proportion of facilities using $\geq 5 \%$ contract FTE RNs and LPNs more than tripled. Use of contract nurses was associated with more deficiency citations, characteristics of poorer facilities and tight labor markets. Nursing homes increasingly rely on contract nurses. The failure of nursing homes to attract and retain a competent, stable workforce creates a vicious cycle of nursing home staffing practices, which may lead to decline in quality of care.
\end{abstract}


Introduction

Nursing homes have long suffered from the lack of an adequate and stable supply of licensed nursing staff. Nursing home staffing vacancies, many of which result from continuously high turnover rates and low job satisfaction, are traditionally difficult to resolve (Wunderlich, Sloan, and Davis 1996; Institute of Medicine 2001). Nursing homes are unattractive worksites for licensed nurses, due in large part to lower salaries, higher burden of administrative duties, and a general lack of prestige among colleagues and society (Wunderlich, Sloan, and Davis 1996; Sherer July/August 2001). The current nursing shortage, which is predicted to be severe and of long duration (Steinbrook 2002), particularly threatens the quality of care in nursing homes (Sherer July/August 2001).

One solution to institutional staffing shortages is the use of temporary or contract nursing staff. This type of staffing is costly, disrupts continuity of care (Guillard 2000), and may also contribute to poor patient care. Indeed, the use of contract nursing staff in nursing homes reinforces the impression that nursing homes provide poor quality care. 
New Contribution

Improving the quality of nursing home care relies heavily on the nursing staff available to plan and deliver around-the-clock care. Although many have studied nursing home staffing patterns (Harrington et al. 1998; Harrington, Kovner et al. 2000; Harrington, Zimmerman et al. 2000), none have considered implications associated with the use of contract licensed staff. Contract staff often receive higher wages and have greater flexibility with working hours and sites than their permanent staff counterparts. Intuitively, licensed nurses would prefer these more lucrative contract arrangements. However, the use of contract licensed staff may increase institutional costs and negatively influence the quality of care.

The lack of empirical data related to contract licensed staff in nursing homes deserves attention. The purpose of this paper is to characterize the extent to which nursing homes use contract registered nurses $(\mathrm{RN})$ and licensed practical nurses (LPN); to determine what kinds of nursing home market situations foster the use of contract RNs and LPNs; and to relate use of contract nursing staff to quality of care in nursing homes indicated by health deficiency citations. 


\section{Background}

Nursing home staffing crisis

The Institute of Medicine identified that nursing home care could be improved by increasing registered nurse staffing, but stopped short of recommending minimum staffing levels (Wunderlich, Sloan, and Davis 1996). Some experts maintain that minimum staffing levels are necessary for quality care (Harrington, Kovner et al. 2000). Federal policy sets mandatory guidelines for basic staffing levels in nursing homes to ensure that sufficient nursing staff are available to provide required care (Decker, Dollard, and Kraditor 2001). These guidelines require a licensed charge nurse on every shift, an RN on staff at least one 8-hour shift each day of the week, and a full-time RN Director of Nursing, who may serve as the charge nurse in smaller facilities. At this writing, thirty-seven states mandate staffing levels beyond the federal guidelines (Health Care Financing Administration 2000; Center for Medicare \& Medicaid Services 2002). Policies that impose minimum staffing levels place further burden on homes to provide defined numbers and types of staff and may force nursing homes to increase their use of contract nursing staff.

Other external factors, such as the widespread nursing shortage (Steinbrook 2002), may influence nursing home staffing decisions. Although the major focus of concern recently has been on the lack of hospital registered nurses, the growing shortage of RNs threatens nursing homes as well (McKeon 2001; Decker, Dollard, and Kraditor 2001). Contributing to the shortage are a lack of specialty training, the aging nursing workforce, declining enrollment in nursing schools, and the decreased attractiveness of health care careers. Another important contributor to the shortage in hospitals is increasing job dissatisfaction among RNs (Aiken et al. 2001). This may also apply to RN staff in nursing homes. 
The National Sample Survey of Registered Nurses (Spratley et al. 2001) reported that only $65 \%$ of registered nurses employed in nursing homes were satisfied with their jobs. More importantly, job satisfaction among those working as staff nurses in nursing homes was lowest of all work settings. Lower levels of job satisfaction have been linked with increased likelihood of turnover (Pan et al. 1995). A recent survey reported annualized turnover rates for nursing home staff RNs and LPNs at 56.2\% and 53.6\%, respectively (American Health Care Association 2002). The complex interplay of mandated staffing levels, professional workforce shortage, dissatisfied workers, and licensed staff turnover points to a potentially escalating trend of using temporary workers to meet institutional needs.

\section{Nurse Contracting}

Contracted nursing staff can be used to contain costs and to fill staffing vacancies. Commonly known as agency nurses, contract nursing staff are thought to contain costs by allowing flexibility in scheduling, decreasing the use of over-time for regular staff, and reducing the need to create more permanent positions (Strzalka and Havens 1996). Staffing demands created by emergencies, holidays, and unscheduled absences may require the use of contract nursing staff. During times of workforce shortages, contract nursing staff are used to ameliorate conditions caused by permanent positions that go unfilled. Recent concern about a widespread nursing shortage led the American Organization of Nurse Executives to survey 693 hospital nurse executives (American Organization of Nurse Executives and the HSM Group 2002). More than half $(54 \%)$ reported using contract staff. No comparable recent data were found for the nursing home industry, although one anecdotal report indicates that following a merger a new corporation discovered two facilities spent $\$ 150,000$ annually on contract staff and a Delaware 
survey found that $100 \%$ of nursing homes used contract staff (Hegland 1992). Nevertheless, the use of non-permanent staff across settings may be a pervasive issue.

Institutions usually contract temporary nursing personnel through staffing agencies (Bloom, Alexander, and Nuchols 1997). Agencies assume responsibility for credentialing these workers. Agencies may also assess work history and technical competencies. Depending on individual state laws, agencies may perform drug screens or criminal background checks as well. Many speculate about the quality of contract nurses and the oversight they receive. Contract workers' lack of familiarity with patients and organizational policies and procedures are frequently cited as problems associated with relying on these types of staff (Sheridan, Bronstein, and Walker 1982; Strzalka and Havens 1996; Bloom, Alexander, and Nuchols 1997; Louwe and Kramer 2002). Professional guidelines regarding principles for nurse staffing in all settings were recently issued (American Nurses Association 1999). Among these were recommendations to document competencies expected of contracted nurses and to conduct ongoing evaluation of the use of supplemental staffing, thus casting doubt on the quality of care provided and management practices that rely on contracted staff.

Hospital staffing studies direct some attention to the use of temporary staff. A study of occupational exposure to blood revealed that nurses working temporary assignments were more likely to sustain injuries from needles or other sharp instruments (Aiken, Sloane, and Klocinski 1997). Temporary assignment of nursing staff to a burn unit was significantly associated with spread of Methicillin-resistant Staphylococcus aureus among patients (Arnow et al. 1982). Another study evaluated the quality of care on one unit by comparing documentation by unithired, float pool, and contract nurses on clinical quality indicators (Strzalka and Havens 1996). The use of contract RNs was associated with increased non-personnel hospital costs calculated as 
operating expenses minus wages and benefits (Bloom, Alexander, and Nuchols 1997). Limited empirical information about the quality of care provided by contracted staff in nursing homes exists. Studies of nursing home staffing and its relationship to quality fail to differentiate permanent and contract staff (Harrington, Zimmerman et al. 2000; Harrington et al. 2001; Harrington et al. 1998). Although a report to Congress contained case studies of nursing home staffing that included attention to the use of contract staff (Louwe and Kramer 2002), the report noted that care provided by contracted staff appeared to depend on the overall quality of care provided by facility staff. This contradicted the regular staff's commonly held perspective that contracted staff contributed to poor quality care.

Based mainly on hospital literature, it appears that care provided by contract staff is negatively perceived by on-staff peers, may be a marker for overall nursing care quality, leads to increased workplace injury and spread of infection, and uses more institutional resources. In light of the inattention given to licensed nurse contracting in nursing homes and the potential quality ramifications resulting from the use of this type of personnel, a careful examination of the issue is necessary. We, therefore, provide a broad overview of the use of licensed contract staff in nursing homes. 


\section{Conceptual Model}

The conceptual framework guiding this analysis is resource dependency theory. Resource dependency theory characterizes the environment in terms of other organizations that the focal organization engages in exchange relationships (Thompson 1967; Pfeiffer and Salancik 1978). Most organizations depend on the resources traded in these exchanges for survival, and they will make the necessary accommodations to guarantee exchange relationships with other organizations. Thus, organizational decision-making, including staffing decisions, may reflect accommodations intended to secure a stable flow of resources from the environment (Oliver 1990). For example, nursing homes depend on sources of referral, such as hospital discharge planners and case managers, in order to secure a key resource, nursing home admissions. However, admission referrals are conditioned on the facility's reputation for providing a level of care adequate to meet the needs of the potential resident. Contributing to this reputation is the maintenance of adequate staffing levels, either through hiring nurses on a permanent basis or through contractual arrangements.

Differences in operating environment and in organizational characteristics will mediate the need and the ability to respond to key constituents. According to theory, dependency on external constituencies is not problematic if resources are sufficient. However, environments vary with respect to munificence, that is, the abundance of resources. The lower the environmental munificence, the more difficult it is to obtain needed resources to make infrastructure investments, such as (in the case of nursing homes) hiring permanent staff to meet minimal staffing levels. This suggests that nursing facilities in low munificence environments will be more likely to contract for staff. 
Munificence is a function of competition and regulatory stringency. The more competitive the environment, the greater the demand on a shared pool of resources (in this case licensed nursing staff) and the more critical the ability to accommodate to the needs of key constituents (Pfeiffer and Salancik 1978; Ulrich and Barney 1984). Similarly, more stringent regulatory requirements may make resource acquisition problematic. Thus, the least munificent environments have high regulatory stringency and a scarcity of licensed staffing.

With respect to licensed nurse scarcity, while it is true that the nursing shortage affects all health care service sectors, because nursing homes are relatively unattractive places to work compared to hospitals, they experience disproportionate difficulties in hiring and retaining fulltime licensed staff. This in turn may create greater dependence on the use of contract licensed staff. Low munificent environments will have the least investment in infrastructure. Thus, we hypothesize that the lower the supply of licensed nurses in the local market, and the greater the competition for that scarce resource from hospitals and other nursing homes, the more likely that facilities will use contract licensed nurses. In addition, to the extent that nursing homes compete for residents on the basis of quality, competition among nursing facilities, controlling for nurse supply, will result in greater use of contract licensed staff. On the other hand, in markets with higher rates of unemployment, there will be fewer job options for licensed nurses, making job retention a priority. Higher rates of unemployment should, therefore, be associated with lower turnover of permanent licensed nursing staff and hence, lower dependence on contract licensed nursing staff. Finally the implementation of the Prospective Payment System for Skilled Nursing Facilities (PPS for SNFs), because it provides incentives to increase the level of case mix acuity and hence the demand for skilled nursing care, should also be associated with greater use of contract licensed staff. 
Organizational characteristics play a mitigating role in attempts to achieve a favorable position within the operating environment. While one hospital study suggests that the use of contract nurses increases non-personnel operating costs, in the short run it allows for greater flexibility by avoiding the costs associated with recruiting and hiring permanent staff. We hypothesize facilities that operate on a for-profit basis, that are chain members and that have a higher proportion of Medicaid recipients in overall resident census (implying a poorer revenue mix) may be inclined to pursue short-term cost advantages through the use of contract licensed staff. On the other hand, facilities with a higher proportion of private pay residents have a more favorable revenue mix, and the additional resources this provides may allow them to hire permanent staff rather than to rely on contract licensed staff. Finally, controlling for nurse supply, higher case mix acuity will increase reliance on contract licensed staff to maintain minimum staffing levels. 
Data Definitions and Sources

Data and Sample

The On-line Survey Certification and Reporting System (OSCAR) files served as the primary source of data. The OSCAR includes organizational and aggregated resident data routinely collected as part of the annual licensure and certification process. We compiled a longitudinal data file from 1992 through 2002 containing 176,509 OSCAR survey records from 18,544 freestanding and hospital-based nursing facilities in urban and rural counties nationwide. We then merged the longitudinal file with the Area Resource File (ARF) for the same years (1992-2002) matched by county indicators to obtain county level market data.

Collected and maintained by the Centers for Medicare and Medicaid Services (CMS), the OSCAR data are used to certify whether Medicare and/or Medicaid participating nursing homes are in compliance with federal regulatory requirements. Certification is achieved through routine facility surveys, which the CMS contracts with states to conduct. Nursing homes are subject to unannounced standard surveys, on average about once a year but no later than 15 months after the date of the previous standard survey.

Upon receiving current provider records from CMS, we linked these records over time for each facility to create a longitudinal OSCAR file. A facility's provider number changes every time it changes ownership or certification category, or terminates from the certification process. We used information on facility name, address, size, associated provider numbers and dates to determine whether survey records under different provider numbers actually refer to the same facility, and if so, assigned them the same facility identifier. This way, we created a unique, longitudinal identifier for each facility in OSCAR. In the cases of facility terminations, the existing data did not provide detailed enough information (e.g., specific reasons for termination, 
length of termination, and whether the facility actually closed down during the termination or not) to determine whether the change resulted in a new facility, or the facility remained essentially the same place under a new number. Nevertheless, evidence to date suggests that our decision rules implemented in the current procedure have worked remarkably well, despite the potential bias toward assuming that length of closure is of relatively little importance compared to name/address information.

We restricted our analysis to freestanding nursing facilities, both urban and rural. We excluded surveys for facilities in Alaska, District of Columbia, Hawaii, and Puerto Rico, due to the small number of cases in these states/entities ( $\mathrm{N}=226$ surveys from 51 freestanding facilities). We excluded an additional 594 facilities that changed freestanding or hospital-based status at any time between 1992 and 2002. This resulted in a final sample of 153,015 surveys from 15,717 distinct freestanding nursing facilities located in 822 urban counties and 1,976 rural counties. Approximately $25 \%$ of facilities changed hands at least once over the study period (1992-2002). Annually, about $3 \%$ of facilities experienced an ownership change. Relatively few facilities, approximately $1 \%$ per year, exited OSCAR over the study period due to termination from Medicare/Medicaid programs. We conducted sensitivity analyses with and without those terminated facilities and found that facility dropouts did not compromise the results reported here. Thus, all available surveys up to termination of those facilities were included in the analysis.

\section{$\underline{\text { Variable Specification }}$}

We separately examined two dependent variables, the use of contract registered nurses (RN) and contract licensed practical nurses (LPN). Given that substantial use of RN and LPN 
contracting is rare, for each we defined a dichotomous measure to indicate whether a facility used 5\% or more contract RNs or LPNs out of total Full-Time Equivalent (FTE) RNs or LPNs.

According to OSCAR instructions and definitions with regard to facility staffing, facilities are asked to report the specific number of hours worked providing various services over the recent two-week period, separately by hours worked by full-time, part-time, and contract staff. The contract category includes individuals under contract (e.g., an RN) as well as organizations under contract (e.g., an agency to provide RNs). In the latter case, hours worked for the individuals provided are recorded. Based on reported staff hours, the number of FTE staff of a particular type can be derived, assuming full-time to be 35 hours worked per week.

Overall, the use of contract nursing staff is relatively rare. In addition, the distribution of $\%$ contract RNs and \% contract LPNs is extremely skewed. Therefore, we categorized the dependent variable. There are alternative approaches to categorization, of course. For example, a lower percentage (than 5\%) can be used as the threshold; a dichotomy for having any versus none contract staff may also be considered; or, it is possible as well to specify a multinomial outcome. Our primary interest in this paper, however, is to look at those "heavy users" of contract nursing staff, i.e., those with $5 \%$ or more of their nursing staff being on-contract.

Facility level variables. Dichotomous variables included for-profit status and chain membership. We also included an interaction term to test the effect of being for-profit and nonchain. We created two variables to represent payer source mix related to reimbursement through Medicaid and private pay using the top decile of the aggregate distribution for each. Therefore, a facility was determined to have a high proportion of Medicaid residents if the proportion of Medicaid residents in the total resident census exceeded $91 \%$ and a high proportion of private pay residents if the proportion of private pay among all residents exceeded 55\%. Low occupancy 
rate for facilities was defined as below $85 \%$ of capacity. Facility size was measured by the total number of beds, centered at the aggregate mean, 109, with increments of 10 beds. We dichotomized these variables because we expected some threshold effects. This also eases interpretation of results in the form of odds ratios. The cutoff points for percent Medicaid (91\%) and percent private pay (55\%) represent the upper decile values in the aggregate (over 19922002) distribution of the respective variable. The cutoff point for low occupancy rate (85\%) corresponds roughly to the lower quartile value of the aggregate distribution of facility occupancy rate. We focused on just those extreme cases of these variables.

Case mix complexity was measured by three indicator variables: (1) facilities providing rehabilitation services to a higher volume of residents, that is having 35 or more rehabilitation residents and $30 \%$ or more residents receiving rehabilitation services, or having 20 or more rehabilitation residents and $50 \%$ or more residents receiving rehabilitation services (Berg, Intrator, and Lemon 2001; Zinn et al. 2003); (2) facilities with any residents receiving IV therapy; and (3) facilities with any residents receiving tracheotomy care (Zinn, Mor, and Gozalo 2000). We categorized some of the continuous variables given our belief that their relationships to the use of contract nursing are not linear but may be best expressed by the presence of a threshold effect.

Market level variables. We selected the following variables to characterize the market environment in which a facility operates (i.e., county), all centered at their aggregate mean with proper increments: overall unemployment rate, centered at $6 \%$; total number of nurses (RNs and LPNs combined) per 1000 population, centered at 4; total number of nursing home beds per 1000 population aged 65 or older, centered at 68 with increments of 10 beds; total number of hospital beds per 1000 population, centered at 4; average number of empty nursing home beds, centered 
at 11 with increments of 10 beds; Herfindahl Index, centered at 0.46 (mean) with increments of 0.32 (one standard deviation); and an indicator for urban location. The Herfindahl Index is a measure of market concentration of nursing home beds, standardized to range $0-1$. The higher the index, the greater extent of market concentration, and hence, less competition.

In addition, we included a dummy variable, indicating whether the survey date was post July 1, 1998 (when the Prospective Payment System [PPS] took effect), to determine if there was a PPS effect on the use of contract licensed nursing staff. We also included a variable for calendar time in years from January 1, 1992 to the current survey to control for unmeasured changes that occurred over time. Furthermore, we controlled for the state where a facility is located by specifying 47 dummy variables, with Alabama as the reference state, to account for unobserved, state-specific characteristics that may affect the use of contract licensed staff in nursing homes.

Because one of the key market variables, total number of nurses per capita in county, was not available in ARF until 1994, the multivariate analysis used data only for the period 19942002. A description of all variables included in the multivariate model, including their aggregate means and standard deviations, is provided in Table 1.

[Insert Table 1. about here] 
Analytic Methods

Our approach was primarily descriptive. We first delineated the trend in the use of contract nursing staff in freestanding nursing facilities over the period 1992-2002. Next, we related contract nursing to quality indicated by the total number of health related deficiencies summarized from the OSCAR data. There is considerable variability across the states in the number of deficiencies and in how state inspection agencies determine specific deficiency citations (Office of Inspector General 1999) which limits the comparability of deficiencies among states. Thus we ranked all facilities within each state in each year by their total number of health deficiencies, and those ranked in the top quartile were identified as providing poor quality of care.

Finally, we conducted a multivariate analysis to examine the effects of various facilityand market-level factors considered relevant to facility leadership's choice to rely on contracting for more than $5 \%$ of their skilled nursing care needs. Specifically, using the XTGEE procedure available in STATA (Stata Corporation 2003), we estimated a Generalized Estimating Equation (GEE) model of the likelihood of using 5\% or more contract licensed nursing staff, separately for RNs and LPNs. Because the outcome is dichotomous, the binomial distribution using the logit link function was specified. Unlike the conventional linear regression model, XTGEE properly accounts for within-group (here facility) correlations, which is suitable for analysis using crosssectional time series data like OSCAR. In addition, the procedure allows specification of the commonly used Huber/White/sandwich estimator of clustered robust variance, which produces valid standard errors even if the within-group correlations are not as hypothesized by the specified correlation structure. In this analysis, an exchangeable or equal correlation structure 
was assumed and the Huber/White robust variance estimator applied. The equation of the crosssectional time series GEE model with a logit link function is given by:

$$
\operatorname{Ln}\left\{\mathrm{P}_{i t} /\left(1-\mathrm{P}_{i t}\right)\right\}=\beta_{0}+\beta \mathrm{X}_{i t}
$$

Where $\mathrm{P}_{i t}$ is the probability of using $5 \%$ or more licensed contract RNs (or LPNs) in facility $i$ at time $t, \beta_{0}$ is the intercept, $\mathrm{X}_{i t}$ is a vector of covariates at the facility and market levels as specified above, and $\beta$ is a vector of parameter estimates for the effects of the covariates. 
Results

$\underline{\text { Sample Characteristics }}$

Descriptive statistics for selected facility level variables based on a cross section of the most recent OSCAR for each facility included in the analysis are provided in Table 2. Ten percent of facilities surveyed reported using $\geq 5 \%$ contract RNs, whereas $14 \%$ used $\geq 5 \%$ contract LPNs. Nearly three-quarters of the sample (73\%) were proprietary and 55\% were part of a chain. Less than $25 \%$ of residents paid privately for their care, while $66 \%$ had Medicaid as the primary source of payment. The overall occupancy rate in this sample was $84 \%$. The mean number of residents per facility was about 91 . The average ratio of FTE LPNs to RNs was 5:1.

[Insert Table 2. about here]

\section{$\underline{\text { Facility Trends Using Contract Nurses }}$}

Figure 1 presents the proportion of facilities using 5\% or more contract RNs and LPNs in each year between 1992 and 2002. As is apparent, contracting for over 5\% of LPNs is somewhat more common than contracting for $5 \%$ or more of RN FTEs. The two figures move in parallel, with a drop between 1992 and 1996 and then a substantial upswing in both rates up to 2002. The gap between the use of contracted LPNs and RNs persisted and widened steadily as the overall use of contracted staff rose sharply from 1997 to 2002.

[Insert Figure 1. about here]

\section{Quality of Care and Contract Nurses}

Figure 2 displays the annual proportion of facilities in the top quartile of intra-state distribution of total heath deficiencies, by whether or not the facility used $5 \%$ or more contract nursing staff (RNs and LPNs combined). As can be seen, facilities employing a higher proportion of contract nurses ( $\geq 5 \%$ of total FTEs) fell disproportionately into the top quartile 
ranks of health deficiency citations during annual survey and certification inspections. For each calendar year the differences between the two groups were statistically significant at the .05 level using Chi-square analyses.

[Insert Figure 2. about here]

\section{$\underline{\text { Facility Characteristics and } \geq 5 \% \text { Contract Licensed Staff }}$}

Table 3 displays results of the two XTGEE analyses for the likelihood of using 5\% or more contracted FTE RNs and LPNs, respectively. For profit facilities were 33\% less likely to use $\geq 5 \%$ contracted RNs and $45 \%$ less likely to contract for $\geq 5 \%$ LPNs $(p<.01)$ than were nonprofit facilities. Facilities with a high proportion of private pay residents were also less likely to employ $\geq 5 \%$ contract licensed $\mathrm{RNs}(\mathrm{OR}=0.88, \mathrm{p}<.05)$. Chain membership increased the likelihood of using $\geq 5 \%$ FTE contract RNs (OR = 1.31, p<.01) and LPNs $(\mathrm{OR}=1.21, \mathrm{p}<.01)$. Facilities that were for-profit without chain membership were also more likely to use $\geq 5 \%$ contract RNs $(\mathrm{OR}=1.24, \mathrm{p}<.01)$ and LPNs $(\mathrm{OR}=1.24, \mathrm{p}<.01)$. Facilities with low occupancy rates were more likely to use $\geq 5 \%$ contracted $\mathrm{RNs}(\mathrm{OR}=1.24, \mathrm{p}<.01)$ and $\mathrm{LPNs}(\mathrm{OR}=1.16$, $\mathrm{p}<.01)$. Larger facilities were also more likely to employ $\geq 5 \%$ contracted $\mathrm{RNs}$ and LPNs (OR = $1.02, \mathrm{p}<.01$ and $\mathrm{OR}=1.02, \mathrm{p}<.01$, respectively, relative to an increment of 10 beds above the mean). The availability of IV therapy was the only case-mix acuity measure that significantly increased the likelihood of empolying $\geq 5 \%$ contract $\mathrm{RNs}(\mathrm{OR}=1.09, \mathrm{p}<.01)$.

\section{$\underline{\text { Market Characteristics and } \geq 5 \% \text { Contract Licensed Staff }}$}

Facilities located in counties with higher unemployment rates were less likely to use $\geq 5 \%$ FTE contracted RNs and LPNs $(\mathrm{OR}=0.97, \mathrm{p}<.05$ and $\mathrm{OR}=0.96, \mathrm{p}<.01$, respectively, relative to $1 \%$ increase in unemployment rate). The number of nursing home beds/1000 persons aged 65 years or older significantly reduced the likelihood of using $\geq 5 \%$ LPNs, while less significantly 
for $\geq 5 \%$ RNs $(\mathrm{OR}=.96, \mathrm{p}<.01$ and $\mathrm{OR}=0.97, \mathrm{p}<.05$, respectively, relative to an increment of 10 beds above the mean). For each increment of 10 nursing home bed vacancies above the aggregated county mean (11 empty beds), facilities were $9 \%$ more likely to employ $\geq 5 \%$ FTE contract LPNs $(\mathrm{OR}=1.09, \mathrm{p}<.01)$. A significant and negative effect of the Herfindahl Index on LPN contracting suggests that facilities in more competitive markets (i.e., less concentrated places) were more likely to use $\geq 5 \%$ contract LPNs.

Compared with rural facilities, urban facilities were significantly more likely to engage in contracting $\geq 5 \%$ RNs $(\mathrm{OR}=1.82, \mathrm{p}<.01)$ and to contract for more than $5 \%$ of their LPN FTEs $(\mathrm{OR}=2.02, \mathrm{p}<.01)$. Consistent with Figure 1, after the introduction of PPS, facilities were substantially more likely to use $\geq 5 \%$ FTEs for both contract RNs $(\mathrm{OR}=1.55, \mathrm{p}<.01)$ and LPNs $(\mathrm{OR}=1.39, \mathrm{p}<.01)$. Although many time-varying facility and market characteristics were controlled for, a linear calendar time trend was still apparent with an increase of $13 \%$ in the odds of using $\geq 5 \%$ contract RNs and $16 \%$ increase in the odds of using $\geq 5 \%$ contract LPNs for every year.

[Insert Table 3. about here] 


\section{Discussion}

Nursing homes appear to be contracting for licensed staff more and more as financial and workforce pressures have increased over the past decade. Between 1992 and 1996, contract licensed nursing staff use declined but it increased in 1997, with proportions tripling by 2000. Whether this trend was caused by the introduction of the prospective payment system (PPS) in nursing homes or was further complicated by the emergence of the nursing shortage is unclear. Nevertheless, it appears that both have influenced the manner in which nursing homes are staffed. Recent Health Resources and Services Administration survey results suggest that nursing homes are the least desirable work places for nurses to work (Spratley et al. 2001). This may also account for the dramatic increase in the use of contract licensed staff during the final years of the last decade.

No definitive studies to date support the common perception that contract nursing staff provide lower quality care. Our findings indicated that facilities that used a greater proportion of contract licensed staff $(\geq 5 \%)$ were more likely to receive the worst quality deficiency ratings. More health deficiencies and staff instability would certainly reinforce the notion that nursing homes are not desirable work places for nursing staff. The use of contract licensed nursing staff in nursing homes is not random. It reflects regional (rural vs. urban) and market (unemployment rate, nursing home beds per capita aged 65 years and older) variation. In addition, the use of contracted staff reflects individual characteristics of nursing facilities. These are particularly evident in their proprietary status, size and occupancy rates, as well as in the reimbursement mix (Medicaid vs. private pay) of the facility's residents.

Economic motivations may underlie the decision to use contract licensed staff in U.S. nursing homes. The Balanced Budget Act of 1997 established a prospective payment system 
(PPS) for nursing homes that modified payment for skilled nursing facility services. The effect of PPS on nursing home staffing decisions may very well be real. In times of economic uncertainty, organizations may desire to avoid new staffing obligations even if it results in temporary increases in labor costs (Zinn et al. 2003). In addition, proprietary nursing facilities are less likely to use $\geq 5 \%$ FTE contract licensed nursing staff, thereby avoiding higher labor costs associated with this type of worker. This finding suggests two possibilities. Rather than paying premium prices to complement their existing pool of licensed staff in situations of staff illness and vacancies or when bed occupancy fluctuates, proprietary facilities may be more willing to operate with fewer licensed staff on site. On the other hand, proprietary nursing homes may have resources that enable them to create better work environments, thus leading to a more stable workforce and less turnover as demonstrated in hospital staffing studies (Aiken et al. 2002; Aiken and Patrician 2000; Aiken, Smith, and Lake 1994). While there is little empirical evidence to suggest that the use of contracted licensed staff in nursing homes is more costly as compared to all the training, recruitment and benefit costs associated with full time nurses, research has demonstrated an increase in operating costs associated with the use of contracted staff in hospitals (Bloom, Alexander, and Nuchols 1997).

The profile of a facility that employs more contract licensed staff appears to be the profile of a poor facility. RN contracting is prevalent in facilities with low occupancy rates, a lower proportion of residents who pay privately for care and those more likely to receive deficiency citations. Facilities with these attributes are more likely to close (Angelelli et al. 2003). The unfortunate reality of limited resources for clinical care among the poorer nursing homes undoubtedly reduces the opportunities for such facilities to attract and retain licensed nursing staff. Facilities with reputations for turnover or chronic unfilled vacancies may be associated 
with poor quality care by licensed nursing personnel. As a result, facilities have difficulty recruiting permanent licensed nursing employees. Thus, a vicious cycle is created. Poorer facilities are forced to allocate higher proportions of their resources to maintain the absolute minimum licensed nursing staff levels needed to remain operational (Mor et al. 2004).

Market level factors also support the notion that staffing decisions are motivated by economic conditions. In urban areas, RN shortages are even more acute than in rural areas. The competition between hospitals, nursing homes, and other agencies for $\mathrm{RN}$ services in these areas are heightened. Furthermore, facilities in more competitive job markets (e.g., counties with higher numbers of empty nursing home beds or lower Herfindahl Index) are more likely to contract for LPNs, while counties with higher unemployment rates discourage both RN and LPN contracting.

The results of this study must be interpreted with the following limitations in mind. We were unable to truly capture patient care quality. Our gross proxy of quality, health deficiency citation, may be compounded because of huge inter-state variations. We attempted to remove this variation by using intra-state rankings and by further controlling for states in the analyses. This maneuver, however, may have failed fully to account for this variation. The same caveat applies to staffing data in the OSCAR, which are highly variable, prone to error, and capture only a two-week period of reporting (Feng et al. 2005). Additionally, it was impossible to differentiate between contracted and "float" staff. The difference between these temporary workers is that "float" staff are generally facility employees who are assigned to work where the need is greatest. This type of staffing decision by nursing homes may have different effects on quality or deficiencies by virtue of the employee being known to staff and by having prior contact with residents. 
Implications

This study is the first to characterize the use of contract licensed staff in nursing homes across the country in terms of the extent to which temporary staff are used, exogenous conditions that encourage these staffing patterns, and how this phenomenon may relate to quality of care. Clearly organizational as well as market factors influence the factors that go into facility administration choosing to contract for nursing staff. While this study has expanded our understanding of the prevalence and factors influencing this phenomenon, further quality of care implications for nursing home residents related to increased use of contract nursing staff warrant more research.

Concern about the use of contract nurses by nursing homes seems to be particularly relevant in light of the growing nursing shortage and current payment structures for nursing home care. Nursing homes have been historically plagued by labor shortages because they are the least desirable employers in terms of wages and working conditions. As the nursing shortage reaches crisis proportions in many labor markets around the country, it will be crucial for administrators and policy makers to know more about when and under what conditions nursing homes rely upon contract nursing staff.

The escalating use of contracted licensed staff in nursing homes has major implications for state and federal policy makers. Results of our analyses suggest facilities that staff with $\geq 5 \%$ licensed contract nursing staff may be contributing to inferior quality of care due to procedural inefficiencies and staff deficits. Payment structures for nursing homes must take into account the complexity of care today's nursing home population requires and the level of staff required to provide appropriate and quality care. The use of contract staff is widely considered to be expensive, of lower quality, and discontinuous. Whether these perceptions are completely 
accurate remains to be seen. Nursing homes that are facing tight labor markets, reduced financial resources, and a reputation of poor quality care stand little chance of attracting a stable work force (Institute of Medicine 2001) or remaining viable (Angelelli et al. 2003). Thus, some of society's most vulnerable population are served by facilities that are indeed vulnerable themselves (Mor et al. 2004). 


\section{References}

Aiken, L. H., S. P. Clarke, D. M. Sloane, J. A. Sochalski, R. Busse, H. Clarke, P. Giovanetti, J. Hunt, A. M. Rafferty, and J. Shamian. 2001. Nurses' reports on hospital care in five countries. Health Affairs 20 (3):43-53.

Aiken, L. H., S. P. Clarke, D. M. Sloane, J. Sochalski, and J. H. Silber. 2002. Hospital nurse staffing and patient mortality, nurse burnout, and job dissatisfaction. Journal of the American Medical Association 288 (16):1987-1993.

Aiken, L. H., and P. A. Patrician. 2000. Measuring organizational traits of hospitals: The Revised Nursing Work Index. Nursing Research 49:146-153.

Aiken, L. H., D. M. Sloane, and J. L. Klocinski. 1997. Hospital nurses' occupational exposure to blood: Prospective, retrospective, and institutional reports. American Journal of Public Health 87:103-107.

Aiken, L. H., H. L. Smith, and E. T. Lake. 1994. Lower Medicare mortality among a set of hospitals known for good nursing care. Medical Care 32:771-787.

American Health Care Association. 2002. Results of the 2001 AHCA nursing position vacancy and turnover survey. Washington, DC.

American Nurses Association. 1999. Principles for nurse staffing with annotated bibliography. Washington, DC: Author.

American Organization of Nurse Executives and the HSM Group, Ltd. 2002. Acute Care Hospital Survey of RN Vacancy and Turnover Rates. Chicago: American Hospital Association.

Angelelli, J., V. Mor, O. Intrator, Z. Feng, and J. Zinn. 2003. Oversight of nursing homes: Pruning the tree or just spotting bad apples? Gerontologist 43 (Special Issue II):67-75. 
Arnow, P. M., P. A. Allyn, E. M. Nichols, D. L. Hill, M. Pezzlo, and R. H. Bartlett. 1982. Control of Methicillin-resistant Staphylococcus aureus in a burn unit: Role of nurse staffing. Journal of Trauma 22:954-959.

Berg, K., O. Intrator, and S. Lemon. 2001. Classification of post-acute care in skilled nursing facilities. Gerontologist 41 (Special Issue I,):270.

Bloom, J. R., J. A. Alexander, and B. A. Nuchols. 1997. Nurse staff patterns and hospital efficiency in the United States. Social Science and Medicine 44:147-155.

Center for Medicare \& Medicaid Services. 2002. Report to Congress: Appropriateness of Minimum Nurse Staffing Ratios In Nursing Homes Phase II Final Report. Department of Health and Human Services 2002 [cited August 5 2002]. Available from http://cms.hhs.gov/medicaid/reports/rp1201home.asp.

Decker, F. H., J. Dollard, and K. R. Kraditor. 2001. Staffing of nursing services in nursing homes: Present issues and prospects for the future. Senior Housing \& Care Journal 9 (1):3-26.

Feng, Z., P.R. Katz, O. Intrator, J. Karuza, and V Mor. 2005. Physician and nursing staffing in nursing homes: The role and limitations of the Online Survey Certification and Reporting (OSCAR) system. Jounral of the American Medical Directors Association 6 (1):27-33.

Guillard, S. 2000. Staff recruitment. Nursing Homes 49 (5):20-22.

Harrington, C., H. Carrillo, J. Mullan, and J. H. Swan. 1998. Nursing facility staffing in the states: The 1991 to 1995 period. Medical Care Research and Review 55:334-363.

Harrington, C., C. Kovner, M. Mezey, J. Kayser-Jones, S. Burger, M. Mohler, R. Burke, and D. Zimmerman. 2000. Experts recommend minimum nurse staffing standards for nursing facilities in the United States. Gerontologist 40:5-16. 
Harrington, C., S. Woolhandler, J. Mullan, H. Carrillo, and D. U. Himmelstein. 2001. Does investor ownership of nursing homes compromise the quality of care? American Journal of Public Health 91:1452-1455.

Harrington, C., D. Zimmerman, S. L. Karon, J. Robinson, and P. Beutel. 2000. Nursing home staffing and its relationship to deficiencies. Journal of Gerontology 55B:S278-S287.

Health Care Financing Administration. 2002. Report to Congress: Appropriateness of Minimum Nurse Staffing Ratios In Nursing Homes. Department of Health and Human Services 2000 [cited August 5 2002]. Available from http://www.hcfa.gov/medicaid/reports/rp700exs.pdf.

Hegland, A. 1992. A new twist to an old concept: Provider opens temporary nursing agency. Contemporary Long Term Care 15 (7):38, 48.

Institute of Medicine. 2001. Improving the quality of long-term care. Washington, DC: National Academy Press.

Louwe, H., and A. Kramer. 2002. Report to Congress: Appropriateness of Minimum Nurse Staffing Ratios In Nursing Homes Phase II Final Report. Department of Health and Human Services 2002 [cited August 5 2002]. Available from http://cms.hhs.gov/medicaid/reports/rp1201home.asp.

McKeon, E. 2001. Nursing home staffing crisis. American Journal of Nursing 101 (5):25.

Mor, V, J. Zinn, J. Angelelli, J. Teno, and S. C. Miller. 2004. Driven to tiers: Socioeconomic and racial disparities in the quality of nursing home care. Milbank Quarterly 82 (2):227-256.

Office of Inspector General. 1999. Nursing home survey and certification: Deficiency trends. New York Region: Department of Health and Human Services. 
Oliver, C. 1990. Determinants of interorganizational relationships: Integration and future directions. Academy of Management Review 11:241-265.

Pan, S., J. Dunkin, K. J. Muus, R. Harris, and J. M. Geller. 1995. A logit analysis of the likelihood of leaving rural settings for registered nurses. Journal of Rural Health 11:106113.

Pfeiffer, J., and G. Salancik. 1978. The external control of organizations: A resource dependence perspective. New York: Harper \& Row.

Sherer, R. A. 2003. How can a nursing shortage be prevented? (Vol. 2, Number 4). Geriatric Times July/August 2001 [cited February 18 2003]. Available from http://www.geriatrictimes.com/g010704a.html.

Sheridan, D. R., J. E. Bronstein, and D. D. Walker. 1982. Using registry nurses: Coping with cost and quality issues. Journal of Nursing Administration 12 (10):26-34.

Spratley, E, A Johnson, JA Sochalski, M Fritz, and W Spencer. 2001. The registered nurse population: Findings from the National Sample Survey of Registered Nurses. Washington, DC: U.S. Department of Health and Human Services.

Stata statistical software 8.0. Stata Corporation, College Station, TX.

Steinbrook, R. 2002. Nursing in the crossfire. New England Journal of Medicine 346:1757-1766.

Strzalka, A., and D. S. Havens. 1996. Nursing care quality: Comparison of unit-hired, hospital float pool, and agency nurses. Journal of Nursing Care Quality 10 (4):59-65.

Thompson, J. 1967. Organizations in action. New York: McGraw-Hill.

Ulrich, D., and J. B. Barney. 1984. Perspectives in organizations: Resource dependence efficiency and population. Academy of Management Review 9:471-481. 
Wunderlich, G., F. Sloan, and C. K. Davis, eds. 1996. Nursing staff in hospitals and nursing homes: Is it adequate? Washington, DC: National Academy Press.

Zinn, J., V Mor, and P Gozalo. 2000. Market and regulatory forces and the transformation of the nursing facility industry. Advances in Healthcare Management 1:369-391.

Zinn, J.S., V. Mor, O. Intrator, Z. Feng, J. Angelelli, and J.A. Davis. 2003. The impact of the Prospective Payment System for skilled nursing facilities on therapy service provision: A transaction cost approach. Health Services Research 38:1467-1485. 
Table 1. Means and standard deviations for variables included in the multivariate analysis, aggregated over 1992-2002 ( $\mathrm{N}=124,297$ surveys from 15,717 freestanding facilities)

\begin{tabular}{|c|c|c|}
\hline & Mean & $\mathrm{SD}$ \\
\hline \multicolumn{3}{|l|}{ Dependent variables: } \\
\hline Contract RNs $\geq 5 \%(1 / 0)$ & 0.05 & 0.23 \\
\hline Contract LPNs $\geq 5 \%(1 / 0)$ & 0.08 & 0.27 \\
\hline \multicolumn{3}{|l|}{ Facility characteristics: } \\
\hline For profit $(1 / 0)$ & 0.73 & 0.44 \\
\hline Chain $(1 / 0)$ & 0.56 & 0.50 \\
\hline For profit and non-chain $(1 / 0)$ & 0.26 & 0.44 \\
\hline$\%$ Medicaid & 66.1 & 22.7 \\
\hline$\%$ private pay & 26.0 & 21.0 \\
\hline Occupancy rate $(\%)$ & 87.0 & 14.4 \\
\hline Bed size & 109.0 & 63.4 \\
\hline IV therapy available $(1 / 0)$ & 0.29 & 0.45 \\
\hline Tracheotomy care available (1/0) & 0.24 & 0.43 \\
\hline High rehab intensity $(1 / 0)$ & 0.05 & 0.22 \\
\hline \multicolumn{3}{|l|}{ Market (county) characteristics: } \\
\hline Unemployment rate $(\%)$ & 5.4 & 2.7 \\
\hline \# Nurses (RNs+LPNs) per 1000 population & 4.1 & 4.0 \\
\hline \# Nursing home beds per 1000 population aged $65+$ & 68.0 & 49.0 \\
\hline \# Hospital beds per 1000 population & 4.0 & 4.4 \\
\hline Average \# empty nursing home beds & 12.2 & 11.0 \\
\hline Herfindahl Index (range 0-1) & 0.46 & 0.32 \\
\hline Urban location (1/0) & 0.30 & 0.46 \\
\hline \multicolumn{3}{|l|}{ Other controls: } \\
\hline Post PPS (survey date after 7/1/1998; 1/0) & 0.50 & 0.50 \\
\hline Calendar time (years from 1/1/1992-current survey) & 6.5 & 2.6 \\
\hline
\end{tabular}


Table 2. Characteristics of 15,717 freestanding facilities included in the final analysis sample based on the latest OSCAR survey

\begin{tabular}{lll}
\hline & Mean & SD \\
\hline Contract RNs $\geq 5 \%(1 / 0)$ & 0.10 & \\
Contract LPNs $\geq 5 \%(1 / 0)$ & 0.14 & \\
Facility is for profit (1/0) & 0.73 & 22.4 \\
Facility is part of a chain (1/0) & 0.55 & 20.0 \\
$\%$ Medicaid & 66.0 & 15.3 \\
$\%$ Private pay & 24.3 & 57.0 \\
Occupancy rate (\%) & 84.3 & 34.8 \\
Total \# residents & 90.5 & 17.1 \\
Total \# FTE RNs+LPNs & 19.3 & 23.0 \\
Total \# FTE RNs & 6.2 & \\
Total \# FTE LPNs & 13.1 & \\
LPN/RN ratio & 5.1 & \\
\hline
\end{tabular}


Table 3. The likelihood of using $\geq 5 \%$ licensed contract nurse staff: Cross-sectional time series GEE model results, OSCAR 1992-2002

\begin{tabular}{|c|c|c|c|c|}
\hline & \multicolumn{2}{|c|}{ Contract RNs: $\geq 5 \%$} & \multicolumn{2}{|c|}{ Contract LPNs: $\geq 5 \%$} \\
\hline & $\beta$ & $\mathrm{SE}^{\mathrm{a}} \mathrm{OR}$ & $\beta$ & $\mathrm{SE}^{\mathrm{a}} \mathrm{OR}$ \\
\hline \multicolumn{5}{|l|}{ Facility characteristics: } \\
\hline For profit & $-0.401 * *$ & 0.0600 .670 & $-0.595 * *$ & 0.0540 .551 \\
\hline Chain & $0.272 * *$ & 0.0671 .313 & $0.191 * *$ & 0.0591 .210 \\
\hline For profit \& Non-chain & $0.219 * *$ & 0.0801 .244 & $0.211 * *$ & 0.0711 .235 \\
\hline High \% Medicaid (>91\%) & $0.112+$ & 0.0611 .118 & -0.021 & 0.0520 .979 \\
\hline High $\%$ private pay $(>55 \%)$ & $-0.133 *$ & 0.0610 .876 & -0.071 & 0.0510 .931 \\
\hline Low occupancy $(<85 \%)$ & $0.213 * *$ & 0.0371 .237 & $0.149 * *$ & 0.0311 .161 \\
\hline Bed size (centered 109, step 10$)$ & $0.016 * *$ & 0.0031 .016 & $0.024 * *$ & 0.0031 .024 \\
\hline IV therapy available & $0.084 * *$ & 0.0301 .088 & 0.038 & 0.0261 .039 \\
\hline Tracheotomy care available & 0.031 & 0.0351 .032 & 0.050 & 0.0311 .052 \\
\hline High rehab intensity & 0.083 & 0.0641 .086 & 0.003 & 0.0551 .003 \\
\hline \multicolumn{5}{|l|}{ Market (County) characteristics: } \\
\hline Unemployment rate & $-0.027 *$ & 0.0120 .973 & $-0.038 * *$ & 0.0100 .963 \\
\hline \# nurses per 1000 population & 0.010 & 0.0091 .010 & $0.013+$ & 0.0081 .013 \\
\hline \# Nursing homes beds per 1000 population $65+$ & $-0.027 *$ & 0.0120 .974 & $-0.038 * *$ & 0.0120 .963 \\
\hline \# Hospital beds per 1000 population & -0.011 & 0.0130 .989 & -0.015 & 0.0110 .985 \\
\hline Average \# empty nursing home beds & -0.018 & 0.0320 .983 & $0.083 * *$ & 0.0271 .086 \\
\hline Herfindahl Index & -0.086 & 0.0530 .918 & $-0.252 * *$ & 0.0520 .777 \\
\hline Urban & $0.597 * *$ & 0.0681 .817 & $0.702 * *$ & 0.0642 .019 \\
\hline \multicolumn{5}{|l|}{ Other controls: } \\
\hline Post PPS (after July 1, 1998) & $0.437 * *$ & 0.0491 .549 & $0.330 * *$ & 0.0401 .391 \\
\hline Calendar time (years $1 / 1 / 92$ — current survey) & $0.125 * *$ & 0.0101 .134 & $0.145 * *$ & 0.0081 .156 \\
\hline \multicolumn{5}{|l|}{ States (47 dummies; omitted) } \\
\hline Intercept & $-6.513 * *$ & 0.3680 .001 & $-5.466 * *$ & 0.356 \\
\hline Model $\chi^{2}$ (Wald) / d.f. / N & \multicolumn{2}{|c|}{$2721.46 / 66 / 121,366$} & \multicolumn{2}{|c|}{3754.34 / 66 / 122,675 } \\
\hline Estimated within-facility correlation (exchangeable) & \multicolumn{2}{|c|}{0.118} & \multicolumn{2}{|c|}{0.165} \\
\hline
\end{tabular}

$+\mathrm{p}<.10 * \mathrm{p}<.05 \quad * * \mathrm{p}<.01 \quad{ }^{\mathrm{a}}$ Adjusted for clustering within facility 